\title{
Screening of Donor and Recipient in Solid Organ Transplantation
}

\section{S. A. Fischer ${ }^{a}, *$ K. Lu ${ }^{b}$ and the AST Infectious Diseases Community of Practice}

a Transplant Infectious Diseases, Rhode Island Hospital. The Warren Alpert Medical School of Brown University, Providence, $R I$

${ }^{\mathrm{b}}$ Center of Evidence-Based Medicine, Division of Urology, Department of Surgery, E-Da Hospital. I-Shou University, Taiwan

* Corresponding author: Staci Fischer,

sfischer@lifespan.org

Key words: Donor infection, donor-to-host transmission, latent infection, prevention, screening, testing

Abbreviations: HBV, hepatitis B virus; HIV, human immunodeficiency virus; $P P D$, purified protein derivative (TB screening test).

\section{Background}

Pretransplant screening of potential organ donors and recipients is essential to the success of solid organ transplantation (1-4). The goals of pretransplant infectious disease screening are to identify conditions which may disqualify either donor or recipient; identify and treat active infection pretransplant; recognize and (if possible) define the risk of infection and develop strategies for preventing and mitigating posttransplant infection; and implement preventative measures, including immunizations (5). While there is general agreement on the major infections for which routine screening is performed, centers vary in the extent of infectious diseases investigation and the actions taken as a result.

Potential recipients should be evaluated for infection risk by obtaining a thorough medical history, including details of prior infections, places of travel and residence, and exposures to animal and environmental pathogens. While all potential recipients undergo screening for the presence of infections such as HIV, hepatitis C (HCV) and cytomegalovirus (CMV), the detailed history can focus additional testing if necessary to mitigate and prevent the reactivation of latent infections posttransplant. Pretransplant recipient screening also helps determine immunity to vaccine-preventable illnesses and may help with allocation of infected donor organs to recipients with known immunity to certain pathogens (6). The pretransplant period is an ideal time for detailed counseling of the recipient and his/her family about safe food handling and the risk of infection associated with pets, travel and hobbies such as gardening and woodworking. Infection prevention approaches including hand hygiene, prophylactic antimicrobials, postexposure prophylaxis and updating of immunizations should be addressed as well.

A variety of pathogens may be transmitted by transplantation (Table 1) (7-10). Previous guidelines for pretransplant screening have been developed by a number of national and international multidisciplinary transplant groups $(6,10-15)$. The Centers for Disease Control and Prevention (CDC) have published guidelines for the prevention of HIV transmission through transplantation (16). These are in the process of revision in order to address updated knowledge of transmission of HIV and other bloodborne pathogens. In addition, the work of the ad hoc United Network of Organ Sharing/Organ Procurement and Transplantation Network (UNOS/OPTN) Disease Transmission Advisory Committee (DTAC) has helped define the risk of infection and disease transmission in organ donation in the United States and shape the discussion of screening and preventive measures $(17,18)$.

While conventional screening strategies are very effective in most cases, they are not a guarantee against donorderived infections. There have been a number of highprofile incidents of donor-transmitted infection reported in recent years, including rabies (19), Iymphocytic choriomeningitis virus (20), West Nile virus (21), HIV (22-24) and $\operatorname{HCV}(23,24)$, which have renewed discussion of the process of organ donor screening. In addition to DTAC, other transplant and public health community initiatives have helped guide practice in the hope of developing a more robust sentinel network to detect and respond to donor transmission events in a more timely manner $(20,25-28)$.

This guideline summarizes current opinions on screening for bacterial, mycobacterial, fungal, parasitic and viral infections in the donor and recipient (Table (2) (5). More detailed discussions of these infections, including posttransplant monitoring, prophylaxis and treatment are found in other sections of these Guidelines.

Due to the lack of expansion in the available organ pool despite steady increases in the need for organ replacement for end-stage diseases, it has become necessary to consider marginal donors, including those with active infection at the time of donation, higher risk serologic profiles, or a 
Table 1: Pathogens reported to be transmitted with solid organ transplantation

\begin{tabular}{ll}
\hline Bacteria & Mycobacteria \\
Staphylococcus aureus & Mycobacterium tuberculosis \\
Klebsiella species & Nontuberculous mycobacteria \\
Bacteroides fragilis & Parasites/protozoa \\
Pseudomonas aeruginosa & Toxoplasma gondii \\
Escherichia coli & Strongyloides stercoralis \\
Salmonella species & Plasmodium species \\
Yersinia enterocolitica & Trypanosoma cruzi \\
Treponema pallidum & Pneumocystis jiroveci \\
Brucella species & Viruses \\
Enterobacter species & Cytomegalovirus \\
Acinetobacter species & Epstein-Barr virus \\
Legionella species & Herpes simplex virus \\
Nocardia species & Varicella-zoster virus \\
Listeria monocytogenes & Human herpesvirus-6 \\
Fungi & Human herpesvirus-7 \\
Aspergillus species & Human herpesvirus-8 \\
Candida species & Hepatitis B, D \\
Coccidioides immitis & Hepatitis C \\
Cryptococcus neoformans & Human immunodeficiency virus \\
Histoplasma capsulatum & Parvovirus B19 \\
Scedosporium apiospermum & Rabies \\
Prototheca species & Lymphocytic choriomeningitis \\
Zygomycetes & virus \\
& West Nile virus \\
& BK virus \\
& Human T cell lymphotropic \\
& virus (HTLV)-1/2 \\
&
\end{tabular}

social history indicating potential exposure to bloodborne pathogens such as HIV or HCV. The natural history and treatment options for donor infection, the urgency of transplantation of a vital organ into a recipient and the likelihood (or lack thereof) of another organ offer for the patient on the transplant waiting list must all be weighed in determining the acceptability of the potentially infected donor.

\section{Donor Screening}

\section{Living donors}

The differences in screening of the living donor and the deceased donor are largely based on the different time constraints during which the evaluation must take place. For the living donor, it is often possible to treat active infection and delay transplantation until the infection resolves. If there is a significant delay between donor evaluation and transplantation, interim evaluation may be indicated to rule out recently acquired infection. Clinical reassessment of the prospective living donor is indicated if clinical signs or symptoms of possible infection occur, particularly any unexplained febrile illness between the time of initial screening and the planned date of transplantation. The CDC has recommended that all living donors be rescreened with HIV serology and HIV nucleic acid amplification testing (NAT) prior to organ donation, to look for evidence of recently acquired infection (29). Similarly,
Table 2: Frequency utilized serologic tests for screening of donor and recipient prior to transplantation

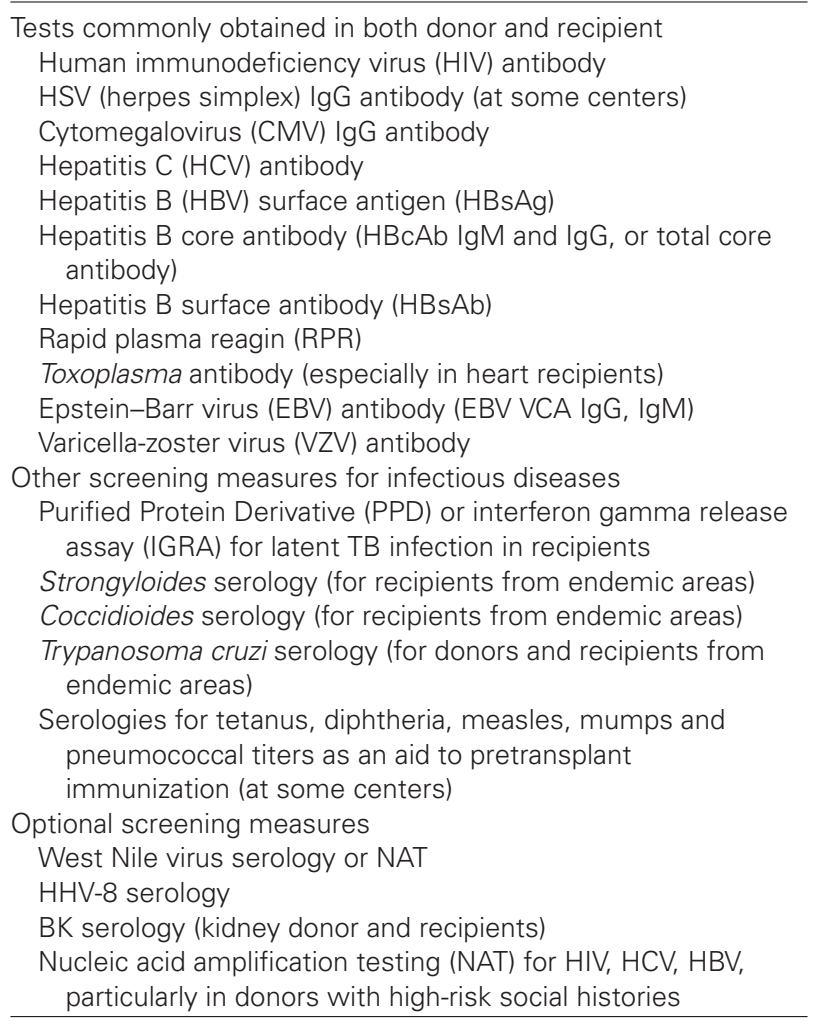

consideration should be given to repeating serologic HBV testing and HCV NAT in the potential living donor with risk factors for these infections.

The screening of a prospective living donor includes a thorough medical and social history, physical examination, laboratory studies including serologic testing (Table 2) and radiographic workup as indicated by the donor's history and the procedure to be performed. The medical history should include an assessment of previous infections, vaccinations, travel and occupational exposures, as well as the presence of behaviors posing risk for bloodborne or sexual pathogen exposure (e.g. drug use, sexual practices, incarceration). Living donors should be screened for syphilis, HIV, hepatitis $B$ and $C$, and tuberculosis via a tuberculin PPD skin test or interferon-gamma release assay (IGRA) (II-2). If there is any suspicious donor history, additional testing may be warranted. Consultation with a transplant infectious disease specialist may help with determining additional workup, counseling and management while awaiting transplantation, should another living donor not be available.

\section{Deceased donors}

By contrast, the time frame for deceased donor evaluation is typically hours. Serologic workup is performed in laboratories associated with organ procurement organizations 
or similar screening agencies (hereafter referred to as OPOs) which operate on a 24-h basis to generate the data needed to determine donor suitability. Because of time constraints and the extensive geographic areas covered by some OPOs, testing is often limited to serologic methods that are rapid and routinely available. Because more sensitive testing may not be available, some infections, such as HIV and HCV, may be difficult to diagnose at an early stage, before the development of specific antibody $(23-25,30)$. Thus, a comprehensive social and medical history on the donor is required to identify risk for infections that might not be detected by serologic testing. Furthermore, certain infections may come to light only after the transplant has been performed, when results of routine procurement cultures of blood, urine and sputum become available. Increasingly, some OPOs are utilizing rapid molecular testing, particularly in high-risk potential donors, including NAT testing for HCV, HBV and HIV. A recent consensus conference on the utility of routine NAT testing was, however, inconclusive, largely due to concerns that testing is not feasible within the deceased donor timeframe in some areas, as well as concern that false positive test results in potential donors with no identified risk factors for infection might result in wastage of viable organs (30). Testing for certain pathogens with particular geographic significance such as Trypanosoma cruzi (Chagas' disease), endemic mycoses and West Nile virus may be performed by some OPOs. If a deceased donor with uncertain risk is to be used, informed consent of the recipient should include the risk for infection transmission.

\section{Donor screening: bacterial infections}

The goal of evaluation of the potential living or decreased donor is to diagnose any infection with the risk of transmission to the recipient(s). Bacterial infections of the respiratory tract, urinary tract or the organ to be transplanted should be treated with documentation of resolution of infection prior to donation. The potential kidney donor with urinary tract infection should be investigated to rule out upper tract involvement. In the potential donor with a history or suspicion of prior bloodstream infection, a thorough investigation should be performed to insure that infection is not present in the target organ.

Syphilis may be latent and asymptomatic in the donor and requires therapy if time permits. Syphilis has rarely been transmitted by transplantation, but it is not a contraindication to organ donation if each recipient is treated posttransplant with an appropriate course of penicillin (31) (II-3).

Deceased donors may harbor known or unsuspected bacterial infections $(6,30-35)$. Attempts to rule out the presence of active infection should include obtaining a detailed history from the donor's family, recent contacts and (if possible) primary care physician, as well as a complete review of medical records, vital signs, physical exam, radiographic studies and any available microbiologic stud- ies. Blood cultures should be obtained to rule out occult donor bacteremia. Bacteremia with virulent organisms such as Staphylococcus aureus and Pseudomonas aeruginosa may result in early posttransplant sepsis or mycotic aneurysm formation at the site of allograft vascular anastomoses (32-36). Although a review of 95 bacteremic donors found no evidence of transmission when recipients were treated with antimicrobial therapy for a mean of 3.8 days posttransplant (36), the standard of care is to administer longer courses of therapy in the recipient (e.g. 2 weeks) if the donor is known to have been bacteremic with a virulent organism (II-2).

In general, there is no reason to treat the recipient of an allograft from a deceased donor with nonbacteremic, localized infection not involving the transplanted organ, with the exception of meningitis, in which occult bacteremia frequently occurs (III). Organs have been successfully transplanted from donors with bacterial meningitis due to pathogens such as Streptococcus pneumoniae when appropriate antimicrobial therapy was administered to both the donor and recipients (37).

Lung transplantation deserves special attention (38). Donor bacterial colonization is common, as the lungs are in contact with the external environment, and the airways are colonized with multiple organisms, with increasing resistance noted in the hospitalized, critically ill potential organ donor. Donor bronchoscopy with cultures performed at the time of evaluation and/or procurement allows for the administration of antibiotics directed at these colonizing organisms, and can prevent invasive infection in the recipient (III) $(7,8,38)$.

Allograft contamination may occur during organ procurement or processing (39). Interpretation of organ preservation solution cultures is challenging, as contamination can occur (39-42); however, infection transmission from contaminated solutions appears to be uncommon $(39,40,42)$. A report of kidney preservation fluid contamination with Candida species in eight recipients demonstrated that the risk of mycotic aneurysm rupture can be mitigated with appropriate antifungal therapy (41).

If a donor is determined to have active bacterial infection at the time of procurement, antibiotics should be administered to each recipient for at least 14 days for infections with Gram-negative bacilli, Staphylococcus aureus, or Candida species (II-3). A shorter course of therapy may be considered for less virulent organisms (III).

\section{Donor screening: mycobacterial infections}

Mycobacterium tuberculosis (TB) has been transmitted by transplantation; in the largest study to date (511 recipients), donor transmission accounted for approximately $4 \%$ of reported posttransplant TB cases (43). Potential living donors should have PPD testing performed (a two-stage tuberculin 
skin test if from an endemic area) or TB interferon-gamma release assay (IGRA) testing (43-45); if either test is positive, additional testing should be performed to rule out the presence of active infection (III). Any donor with active tuberculosis should be excluded from donating until therapy has been completed and all signs of infection have resolved. A positive PPD is defined as the presence (at 48$72 \mathrm{~h}$ ) of $5 \mathrm{~mm}$ or more of induration in immunosuppressed patients or those with contact with a person with active TB; $10 \mathrm{~mm}$ or more in injection drug users, employees or residents of hospitals, nursing homes or other group settings, and children under the age of 4 ; and $15 \mathrm{~mm}$ or more for all others. All potential donors with evidence of latent TB infection (i.e. a positive PPD or a positive IGRA test) should have a chest radiograph to look for evidence of active pulmonary infection. If there are symptoms of infection or radiographic findings suggestive of active disease, acid fast bacilli (AFB) cultures of sputum and/or other appropriate specimens should be performed. In the potential kidney donor with evidence of latent TB infection (LTBI), this could include urine AFB cultures and abdominal CT scanning. If there are no signs or symptoms of active disease and the chest radiograph is normal, sputum AFB cultures are not indicated due to their low yield.

Management of the prospective living donor with LTBI varies with the degree of local endemicity. Delay of transplant until the living donor is treated (with isoniazid for 9 months, rifampin for 4 months, or isoniazid and rifapentine for 3 months) is appropriate, should another suitable donor not be available. In TB endemic areas, where as many as $30-40 \%$ of donors have LTBI, it may be difficult to avoid the use of infected donors. Isoniazid prophylaxis of the recipient of an organ from a living donor with $L T B I$ is an option but controlled studies are needed to determine the efficacy of this practice (III).

In deceased donors, time does not allow for tuberculin skin testing, and the IGRA is not logistically practical in most cases. Donors in whom active tuberculosis is a clinical possibility should not be utilized (II-2). In cases where a potential donor is known to have recent PPD skin test conversion, suggesting recent acquisition of infection with the potential for a high organism burden, transplantation should be approached with caution due to the risk of dissemination in the recipient. Donors with a history of an untreated positive PPD but without evidence of active disease are acceptable, but warrant consideration of treatment of the recipient(s) with isoniazid (III) $(43,45,46)$. New guidelines for the prevention and management of Mycobacterium tuberculosis in organ transplantation have been published in the American Journal of Transplantation (47).

\section{Donor screening: fungal infections}

Active systemic fungal infection in the donor is a contraindication to transplantation. The endemic mycoses may be difficult to diagnose, as infection may be dormant. Trans- mission of histoplasmosis by transplantation has been described (48), but most cases appear to be the result of reactivation of past infection in the recipient. In many individuals from the Midwestern United States, calcified pulmonary, hilar and splenic granulomata are the radiographic residua of old Histoplasma infection, but such signs have not traditionally been considered a contraindication to donation (III). Transmission of coccidioidomycosis by lung transplantation has been reported in the Southwestern United States (49), although reactivation of coccidioidomycosis in the previously infected recipient appears to be far more common (50). There are no uniform recommendations for donor screening for endemic mycoses.

\section{Donor screening: parasitic infections}

Toxoplasmosis is a significant issue in heart transplantation, where the Toxoplasma-seronegative recipient of a Toxoplasma-seropositive heart is at highest risk for developing active toxoplasmosis posttransplant (51-53). Toxoplasmosis has also rarely been transmitted to liver and kidney recipients $(52,53)$. Donor seropositivity is not a contraindication to heart donation but allows for appropriate prophylaxis to be administered to the recipient; routine trimethoprim-sulfamethoxazole prophylaxis against Pneumocystis jiroveci is effective in preventing toxoplasmosis and may negate the need for serologic testing in areas of low prevalence (53). Screening of donors for Toxoplasma is not routinely performed for noncardiac donors but is part of the screening panel at some transplant centers and OPOs.

Transmission of Chagas' disease (Trypanosoma cruzı) by transplantation is a significant problem in endemic areas (Mexico, Central and South America) but has increasingly been reported in the United States (54). A recent consensus conference resulted in recommendations including avoidance of transplantation of the hearts from infected donors and monitoring other recipients with PCR and microscopy of buffy coat to detect early infection and initiate therapy (55).

\section{Donor and recipient screening: viral infections}

As the serologic status of both donor and recipient is crucial in determining the risk of infection, screening for viral infections in both the donor and recipient will be discussed together, and is detailed in Table 3. Caution should be used in interpreting antibody status in infants, due to the role of maternal antibody. More detailed information on the clinical presentation and treatment of these infections is found elsewhere in these Guidelines.

\section{Cytomegalovirus (CMV)}

The CMV serologic status of donor and recipient is an important predictor of posttransplant infection, with the CMV seronegative recipient of a CMV seropositive donor organ $(\mathrm{D}+/ \mathrm{R}-$ ) being at highest risk for development of tissue-invasive $\mathrm{CMV}$, recurrent $\mathrm{CMV}$ and 
Screening of Donor and Recipient in Solid Organ Transplantation

Table 3: Interventions related to donor and recipient screening results

\begin{tabular}{|c|c|c|c|c|}
\hline Pathogen & $\begin{array}{l}\text { Donor antibody } \\
\text { status }\end{array}$ & $\begin{array}{l}\text { Recipient antibody } \\
\text { status }\end{array}$ & $\begin{array}{l}\text { Recommendations } \\
\text { regarding transplantation }\end{array}$ & Comment \\
\hline \multirow[t]{2}{*}{ HIV } & Positive & Negative & Reject donor & $\begin{array}{l}\text { HIV + donors must be excluded in the United } \\
\text { States by law }\end{array}$ \\
\hline & Negative & Positive & $\begin{array}{l}\text { Proceed if HIV well controlled; } \\
\text { be cautious about major } \\
\text { drug interactions between } \\
\text { antiretrovirals and CNIs }\end{array}$ & \\
\hline HTLV-1/2 & Positive & & $\begin{array}{l}\text { Generally exclude HTLV } 1+ \\
\text { donors for organ donation } \\
\text { (may be used in } \\
\text { life-threatening situations, } \\
\text { with informed consent) }\end{array}$ & $\begin{array}{l}\text { Lack of a rapid assay distinguishing HTLV-1 } \\
\text { and } 2 \text { is a significant concern; if HTLV-2 is } \\
\text { confirmed, proceed with transplant. If } \\
\text { confirmed HTLV-1+ would reject donor. }\end{array}$ \\
\hline \multirow[t]{2}{*}{ CMV } & + or - & Positive & Proceed & $\begin{array}{l}\text { D/R status used to determine prevention } \\
\text { strategy (preemptive therapy versus } \\
\text { prophylaxis) }\end{array}$ \\
\hline & Positive & Negative & $\begin{array}{l}\text { Accept; high risk for CMV } \\
\text { infection }\end{array}$ & $\begin{array}{l}\text { See CMV guideline for approach to } \\
\text { management of the CMV D+R- recipient }\end{array}$ \\
\hline \multirow[t]{2}{*}{ EBV } & + or - & Positive & Proceed & \\
\hline & Positive & Negative & $\begin{array}{l}\text { Accept; higher risk for primary } \\
\text { EBV infection and PTLD }\end{array}$ & $\begin{array}{l}\text { Consider posttransplant NAT monitoring to } \\
\text { guide immunosuppression }\end{array}$ \\
\hline \multirow{2}{*}{$\begin{array}{l}\text { Toxoplasma } \\
\text { gondii }\end{array}$} & + or - & Positive & Proceed & TMP/SMX prophylaxis effective in prevention \\
\hline & Positive & Negative & Accept & $\begin{array}{l}\text { Heart transplant donors should receive } \\
\text { prophylaxis with TMP/SMX. If intolerant or } \\
\text { allergic, use atovaquone or dapsone with } \\
\text { pyrimethamine and folinic acid. }\end{array}$ \\
\hline \multirow[t]{2}{*}{$\mathrm{HCV}$} & Positive & Positive & ? Accept & $\begin{array}{l}\text { If used, reserve HCV + organs for recipients } \\
\text { with } \mathrm{Ab} \text { to HCV or severely ill recipient }\end{array}$ \\
\hline & Positive & Negative & $\begin{array}{l}\text { Decision depends on urgency } \\
\text { of transplantation }\end{array}$ & $\begin{array}{l}\text { Some centers accept in severely ill recipient } \\
\text { and/or elderly recipient; controversial in } \\
\text { kidney transplantation }\end{array}$ \\
\hline \multirow[t]{7}{*}{ HBV } & $\mathrm{HBsAb+}$ & + or - & Accept & \\
\hline & $\mathrm{HBsAg}+$ & $-\mathrm{HBsAb}$ & Reject & \\
\hline & & $+\mathrm{HBsAb}$ & Reject & $\begin{array}{l}\text { Some centers use in life-saving situations } \\
\text { with preemptive antiviral treatment of the } \\
\text { recipient }\end{array}$ \\
\hline & $\mathrm{HBcAb}$ & $-\mathrm{HBsAb}$ & Reject & \\
\hline & $\lg M+$ & $+\mathrm{HBsAb}$ & Reject & $\begin{array}{l}\text { Some centers use in life-saving situations } \\
\text { with preemptive antiviral treatment of the } \\
\text { recipient }\end{array}$ \\
\hline & $\begin{array}{l}\mathrm{HBcAb} \text { IgG }+ \text { (with } \\
\text { concurrent } \\
\text { negative HBsAg }\end{array}$ & - HBsAb & $\begin{array}{l}\text { Reject unless for liver } \\
\text { transplant in life-saving } \\
\text { situation }\end{array}$ & $\begin{array}{l}\text { Risk of transmission high, some centers use } \\
\text { with intensive prophylaxis ( } \mathrm{HBlg}+/- \\
\text { antivirals) }\end{array}$ \\
\hline & $\begin{array}{l}\text { and negative } \\
\mathrm{HBcAb} \text { (gM) }\end{array}$ & $+\mathrm{HBsAb}$ & ? Accept & $\begin{array}{l}\text { Some centers accept for extrahepatic } \\
\text { transplants, in immune recipient, with } \\
\text { antiviral prophylaxis }\end{array}$ \\
\hline RPR (syphilis) & Positive & + or - & Accept & $\begin{array}{l}\text { Recipients should be treated for presumed } \\
\text { transmission with penicillin }\end{array}$ \\
\hline $\begin{array}{l}\text { CNS viral } \\
\text { pathogens } \\
\text { (e.g. LCMV, } \\
\text { rabies, WNV) }\end{array}$ & $\begin{array}{l}\text { Clinical suspicion } \\
\text { of infection }\end{array}$ & & Reject & \\
\hline
\end{tabular}

$\overline{\mathrm{CNI}}=$ calcineurin inhibitors; $\mathrm{D}+/ \mathrm{R}-=$ donor seropositive, recipient seronegative; PTLD = posttransplant lymphoproliferative disease; $\mathrm{RPR}=$ rapid plasma reagin; TMP-SMX = trimethoprim sulfamethoxazole.

ganciclovir-resistant CMV (56-58). Consequently, all donors and recipients should be tested for CMV infection using commonly available serologic techniques. While not a contraindication to transplantation, $\mathrm{D}+/ \mathrm{R}-$ status is an indication for more intensive monitoring and prevention strategies posttransplant than in donor/recipient pairs with a lower risk of CMV infection (II-2). The seropositive recipient, regardless of donor status, is at risk for CMV reactivation and usually receives either prophylaxis or preemptive monitoring and therapy. There are many different protocols in use; a full discussion of CMV prevention and treatment is found elsewhere in the Guidelines. 


\section{Fischer et al.}

\section{Epstein-Barr virus (EBV)}

While primary EBV infection can be severe and disseminated in the posttransplant setting, the development of posttransplant lymphoproliferative disease (PTLD) is the most feared EBV-associated complication. The highest PTLD risk is in the EBV seronegative recipient of an EBV seropositive graft, which most commonly occurs in pediatric recipients (59-61). The risk of PTLD can also be increased in the seropositive recipient, especially under the influence of potent immunosuppressants such as antithymocyte globulin (ATG) and belatacept. Awareness of pretransplant serologies helps target the highest risk group for close monitoring by EBV-PCR and preemptive interventions such as decreasing immunosuppression (II-2) (59-61). EBV serology should be performed on all donors and recipients in order to define the risk of posttransplant lymphoma (II-2). The British Transplantation Society and British Committee for Standards in Haematology recently published extensive guidelines on the pretransplant screening and diagnosis of PTLD in organ transplant recipients (62).

\section{Other herpesviruses}

Other herpesviruses of clinical importance in the transplant recipient include herpes simplex virus (HSV-1 and HSV-2), varicella-zoster virus (VZV), human herpesvirus-6 and 7 (HHV-6 and -7), and HHV-8. HSV screening is performed by some centers, whereas other centers administer universal antiviral prophylaxis for at least the first month posttransplant. As primary varicella infection posttransplant can be fatal, VZV screening of the recipient is important, with vaccination of the seronegative recipient pretransplant if at all possible (III).

Recent awareness of the possible roles of HHV-6 and HHV-7 as cofactors for CMV effects, fungal infections and possibly allograft dysfunction has led to increasing interest in these viruses (63). Since almost all adults are seropositive, however, donor and recipient screening for these viruses has not generally been recommended. Whether such screening would be helpful in pediatric transplant programs is unknown. HHV-8, the agent of Kaposi's sarcoma, can reactivate after transplantation and may be transmitted by transplantation (64-66). Seroprevalence varies widely according to the population studied. Optimal strategies for prevention of reactivation have not been defined; thus definitive recommendations for pretransplant screening cannot be made at this time.

\section{Hepatitis B (HBV)}

All donors and recipients should be tested for hepatitis $B$ using standard serologic techniques. The complex issues surrounding HBV and transplantation are discussed in more detail in the hepatitis section of these Guidelines. Donor screening should include at least hepatitis $B$ surface antigen (HBsAg) and HBV core antibody (HBcAb, which should be performed as separate $\lg \mathrm{G}$ and $\lg \mathrm{M}$ to be most useful). Donor HBsAg positivity or HBcAb-IgM positivity indicates active $\mathrm{HBV}$ infection. HBsAg negative, $\mathrm{HBcAb-IgM}$ positive persons may be in the 'window period'; such donors have generally not been utilized, although some centers have used these donors in recipients with evidence of immunity to hepatitis $B$ (those with a positive hepatitis $B$ surface antibody, HBsAb) and/or with intensive posttransplant prophylaxis and monitoring. Isolated HBsAb positivity usually indicates prior vaccination or resolved infection and is not generally considered a risk for HBV transmission.

The most complex question is the use of the HBsAg negative, HBcAb-lgG positive donor ('core-positive donor') (67-69). This may represent either a false-positive test (if isolated $\mathrm{HBcAb}$ positive) or the presence of chronic HBV infection. In the latter, there is a significant risk of transmission of HBV to a liver transplant recipient, and therefore these livers were often not utilized in the past (II-2); however, it has now become more common to transplant livers from $\mathrm{HBcAb}$ positive donors utilizing intensive posttransplant prophylaxis (68). The risk for transmission to extrahepatic recipients appears to be low, but has occurred $(68,70-72)$; this risk can be decreased by pretransplant $\mathrm{HBV}$ vaccination of the recipient. Some centers restrict the use of organs from the core-positive donor to lifethreatening situations and/or vaccinated recipients, or would utilize posttransplant prophylaxis with hepatitis B immune globulin (HBIG) and/or lamivudine if transplanted into a nonimmune recipient (II-3) $(12,13,72)$. Because of the possibility of being offered such an organ, it is prudent to vaccinate all seronegative transplant candidates with HBV vaccine, although the response to this vaccine in patients with end-stage organ disease may be suboptimal, requiring higher doses and repeated injections to attain immunity (III). A donor HBV-DNA level provides helpful information for designing prophylactic strategies, even if the result is received after transplant (14). Additional information on prophylactic strategies may be found in the hepatitis section of these Guidelines (see chapter 16).

Recipient screening for HBV is helpful in posttransplant management. In patients undergoing a liver transplant because of end-stage liver disease due to HBV, there are a variety of posttransplant protocols for prevention of reactivation of HBV, many utilizing HBlg and/or antiviral agents. Extrahepatic transplantation in HBsAg positive recipients has been controversial. In the early days of kidney transplantation, such transplants were performed, resulting in early fulminant hepatitis in some recipients and chronic liver disease in many. Some have maintained asymptomatic status after many years despite evidence of active viral replication (70). With effective antiviral therapies such as lamivudine, adefovir and tenofovir being available, it appears theoretically possible to transplant such recipients more safely (72) although antiviral resistance may become an issue (III). 


\section{Hepatitis C (HCV)}

$\mathrm{HCV}$ infection is frequently chronic, and donors and recipients should be tested for the presence of HCV via standard serologic techniques. HCV is a major indication for liver transplantation, and although $\mathrm{HCV}$ recurrence is common posttransplant, patient and allograft survival are not significantly worse than with other pretransplant diagnoses. HCV seropositive renal transplant candidates are at higher risk for liver disease and sepsis after transplant than are their $\mathrm{HCV}$ seronegative counterparts, but compared with no transplantation as the alternative, the risk is outweighed by the benefit in most cases $(73,74)$. The role of pretransplant treatment of HCV viremia remains under study. Strategies for management of $\mathrm{HCV}$ in the recipient are discussed in detail elsewhere in the Guidelines (see chapter 16).

Utilization of hepatitis $\mathrm{C}$ antibody-positive donors remains controversial, due to the high risk of transmission of HCV through transplantation of any organ. A positive donor HCV NAT (HCV-RNA), indicative of active viral replication, has been associated with a higher risk of transmission, but results of this testing may not be available prior to transplantation from a deceased donor (30). The risk of transmission from NAT negative, HCV antibody positive donors has not yet been fully defined. As recent transmission events have proven, HCV can be transmitted to multiple organ and tissue transplant recipients from a seronegative donor $(23,24)$. The time between infection and antibody production can vary in HCV-infected individuals, although viral RNA is present much earlier than antibody after acute infection. More rapid molecular tests are in development in the hope of clarifying risk from deceased donors prior to a decision to accept an organ. Whenever an HCV seropositive donor is utilized, stringent informed consent is advisable.

\section{Human immunodeficiency virus (HIV)}

HIV-seropositive donors have not been utilized in transplantation, due to the known risk of transmission to the recipient; in the United States, use of HIV seropositive donors is illegal. HIV-1 and HIV-2 serologies are required for all potential donors and recipients; while HIV-2 is rare in the United States and HIV-2 screening serologies are frequently falsely positive, specific testing for this virus should be performed on those donors or recipients from western Africa, where HIV-2 is endemic. Western blot testing should be obtained for confirmation of any positive screening test for either HIV-1 or -2. In the potential living donor with risk factors for HIV exposure but negative HIV serology, NAT testing should be obtained, as these tests become positive prior to the development of a positive antibody test. Due to the efficacy of highly active antiretroviral therapy (HAART), HIV infection in the recipient is no longer a contraindication to solid organ transplantation. Multiple studies worldwide, including a multicenter prospective trial in the United States, have evaluated transplantation in the stable HIV-infected patient $(75,76)$. One- and 3-year graft and patient survival data are compa- rable to non-HIV infected patients undergoing transplantation, but meticulous clinical care and careful attention to pharmacokinetics in the setting of significant drug interactions between immunosuppressive agents and HAART are paramount to success $(75,76)$. While a higher than expected acute rejection rate was noted in 150 HIV-positive kidney transplant recipients, HIV infection remained well controlled and patient and graft survival was comparable to the non-HIV population (76). The complex issues involved in transplanting this population are more fully discussed in the HIV section of these Guidelines (see chapter 17).

\section{Human T-Lymphotropic virus (HTLV-1/2)}

HTLV-1 is endemic in certain parts of the world including the Caribbean, Japan and parts of Africa, and is often asymptomatic. However, infection with HTLV-1 can progress after years or even decades to HTLV-I associated myelopathy/tropical spastic paraparesis (HAM/TSP) or to adult $T$ cell leukemia/lymphoma (ATL); progression occurs in $<1 \%$ and $2-4 \%$ of seropositive individuals in endemic regions, respectively (77-81). HTLV-2 is a virus which is likely more widespread geographically and is serologically difficult to distinguish from HTLV-1, although its association with disease processes is less certain.

Screening for HTLV-1/2 in deceased donors (but not recipients) was standard in US practice until 2009, when UNOS/OPTN discontinued the requirement to perform prospective deceased donor screening, largely as a result of the lack of a serologic test to distinguish HTLV-1 from HTLV-2 (77). Despite its low prevalence in the United States, cases of donor-transmitted infection have occurred, some with significant neurologic and malignant complications (82-85). Graft and patient survival in recipients of HTLV-1/2 seropositive donor organs has been noted to be similar to that of recipients of HTLV-1/2 seronegative organs (79). Western blot testing or NAT may be used to distinguish HTLV-1 from HTLV-2, and may prevent unnecessary wastage of organs from donors with false positive test results or HTLV-2 infection, neither of which should preclude donation $(79,80)$. However, reports from Spain of donor-derived transmission of HTLV-I with rapid development of myelopathy in the recipients suggest that caution should be exercised in the use of HTLV-1 infected donors (82-84). In endemic areas, recipients are often tested for HTLV-1/2 antibodies, although little is known about the course of infection following solid organ transplantation. No cases of HTLV-1 reactivation were observed in a series of Japanese HTLV-1 seropositive recipients undergoing renal transplantation (85).

Emerging or unusual viral infections-West Nile virus, lymphocytic choriomeningitis virus, rabies and SARS It has been increasingly recognized that emerging donorderived viral infections can have an impact on transplant outcomes, with unusually severe presentations in recipients $(19-21,86,87)$. In most cases, an effective screening 
test is not available, so that familiarity with the risks for acquisition and the natural history of these infections is important to assessing offers for deceased donor organs.

West Nile virus (WNV) is a flavivirus which can cause meningoencephalitis, and which has recently appeared in the United States. First reported in 2002, WNV has been transmitted via blood transfusion and solid organ transplantation $(21,87,88)$. It is unclear as yet what the magnitude of the risk of such transmission is, and any risk assessment is complicated by the fluctuating levels and geographic distribution of WNV infection in mosquitoes and humans each year. Serology and PCR for WNV are available but are time consuming. It is prudent to avoid any donor who has had an unexplained febrile illness, mental status changes, or meningitis or encephalitis. Transplant centers should be especially concerned about the use of such donors during times of high prevalence of infection in the region. Since July 2002, all US blood bank products have been tested for WNV using a NAT assay. In the fall of 2003, the US Health Resources and Service Administration (HRSA) issued a Guidance statement regarding organ donors and West Nile virus, which recommended testing all prospective live donors with NAT close to the time of transplant; avoiding donors with any form of unexplained or confirmed WNV encephalitis; and heightened clinical suspicion on the part of the treating clinician for any febrile illness occurring shortly after transplant. NAT poses logistical challenges in some UNOS regions, and is not currently mandated for donor screening. There is also concern that false positive NAT results may lead to a loss of noninfected organs and net loss of life, particularly for liver and heart candidates on the waiting list (89).

Lymphocytic choriomeningitis virus (LCMV): A rodentassociated arenavirus has been reported in several clusters of donor-derived transmission to multiple organ recipients, all but one of which had fatal infection (20,90-92). In one cluster, the outbreak originated from a new pet hamster in the donor's home $(20,90,93)$. To date, despite several similar outbreaks, an effective screening test to rule out infection with LCMV in potential organ donors has not been developed $(20,94)$. The CDC has issued guidelines for minimizing the risk of LCMV related to pet rodents (95). Transplant centers should consider the possibility of LCMV infection in the donor with aseptic meningitis, as well as in the seemingly asymptomatic donor with contact with wild or pet rodents $(10,91)$.

Rabies is another potentially fatal donor-derived infection. In the most well-described outbreak, recipients of transplants from a donor who died of subarachnoid hemorrhage developed rapidly progressive encephalitis; all succumbed to infection (19). Retrospectively, the donor was determined to have had a recent bat bite and was seropositive for rabies virus $(19,96)$. In the United States, rabies is transmitted most commonly by bites, scratches or other saliva exposure from bats, raccoons, skunks or foxes. The rabies and LCMV cases raise the question of whether all donor evaluations should include information about exposure to animals, bites and other environmental exposures to supplement the already detailed information obtained. Because of the highly fatal nature of rabies infection, clinicians are encouraged to avoid donors where even a small possibility of rabies is present.

In 2003, a new respiratory pathogen was reported to cause severe disease with rapid international spread. SARS (Severe Acute Respiratory Syndrome) was found to be due to a previously undescribed coronavirus (SARS-CoV), with nosocomial and household transmission. At least $10 \%$ of affected patients required mechanical ventilation; at least one transplant recipient died of SARS (97). While transmission by transplantation is theoretically possible, the extent of this risk is unknown. Current principles of donor and recipient selection would likely exclude patients with recent acute illnesses meeting SARS criteria; however the consequences of a more remote history of SARS, or a subclinical infection, are unknown. Screening tools for potential adult and pediatric donors were proposed by experts in Toronto (one of the major centers of the 2003 outbreak) which took into account the risk of SARS transmission at the donor's hospital as well as donor's symptoms, travel and contact history (97). If another SARS or a similarly transmitted emerging virus outbreak should occur, this donorscreening algorithm would be useful.

\section{Influenza $A$}

In 2009, a novel influenza virus $\mathrm{A}(\mathrm{H} 1 \mathrm{~N} 1 \mathrm{pdm09})$ caused a worldwide pandemic. Infection was most common in younger patients with severe disease and secondary bacterial infections in pregnant women and those with underlying chronic lung disease, many of whom required intensive care support. The impact on pediatric transplantation was considerable, with prolonged hospitalizations, secondary infections, yet few reported deaths in those who received early antiviral therapy (98). Guidelines for pretransplant screening of potential donors and recipients were published (99). These recommended screening of donors with symptoms consistent with influenza infection; routine screening was not recommended. Due to concern for possible donor transmission, it was recommended that donors who had received adequate antiviral therapy be considered safe for nonlung or small bowel donation. Empiric treatment of the recipients of organs from infected donors with incomplete treatment was recommended (100-102). The pandemic emphasized the need for transplant centers to be vigilant about vaccination of recipients and staff, and to be alert for local outbreaks of disease with the possibility of transmission through transplantation.

Other new and emerging, potentially communicable agents may arise which may affect donor acceptability or recipient activation on the transplant list $(86,87)$. It is advisable to avoid transplantation involving individuals with 
potentially communicable infections for which inadequate information exists to provide appropriate recommendations regarding precautionary measures.

Ancillary screening tests for emerging pathogens, or more sensitive testing for known pathogens, may be proposed by guidelines committees in the future $(8,30,103)$. Such groups will have to consider the feasibility of testing within the limited deceased donor timeframe as well as the risk of false-positive test results which could lead to wastage of otherwise life-saving organs $(88,103)$.

\section{Recipient screening: pretransplant detection of active infection in the recipient}

Transplant recipients are at risk for infections related to complications of end organ failure. Patients awaiting kidney transplantation may have infected hemodialysis or peritoneal dialysis access sites or catheters, or complicated upper- and/or lower-tract urinary infections. Candidates awaiting liver transplants are at risk for aspiration pneumonia, spontaneous bacterial peritonitis, urinary tract infection and infections associated with intravenous catheters. Pancreas transplant candidates can develop diabetic foot infections and associated osteomyelitis. Those awaiting heart transplants may have infections related either to indwelling intravenous catheters, or to ventricular assist devices (VADs) utilized as a bridge to transplantation $(104,105)$. In addition, heart candidates are also at risk for pneumonia in the setting of congestive heart failure and debilitation.

VAD (ventricular assist-device)-associated infections are not a contraindication to transplantation, as complete removal of the VAD at the time of transplant, combined with appropriate posttransplant antibiotic therapy, is often curative $(104,105)$

Screening of lung transplant recipients includes an assessment of colonizing airway flora, and careful review of their previous pulmonary infections (106). Cystic fibrosis patients may be colonized with multi-resistant strains of Pseudomonas and/or Burkholderia cepacia as well as other organisms such as Staphylococcus aureus, Alcaligenes, Klebsiella, Acinetobacter, Stenotrophomonas, Aspergillus and Scedosporium. Knowledge of the pretransplant colonizing flora can assist in developing an individualized peri-transplant prophylactic antimicrobial regimen. There is controversy as to whether patients colonized with Burkholderia should be excluded from receiving lung transplants; molecular typing of Burkholderia isolates may be used to define risk, as genomovar III (B. cenocepacia) is associated with the highest risk of poor outcomes after transplantation (107-109).

\section{Recipient screening: mycobacterial infections}

All patients should have a PPD (tuberculin skin test) performed prior to transplant, and those who have a positive skin test, or a history of active tuberculosis, should undergo additional screening to rule out active disease (II2) (43). Interferon-gamma release assays (IGRAs) may be particularly useful in assessing patients who received Bacillus Calmette-Guerin (BCG) vaccination, as the IGRA assay has the potential to distinguish PPD positivity related to BCG from that related to latent TB infection in those above the age of $5(44,110)$.

Patients with LTBI should be given prophylaxis to prevent reactivation of disease in the setting of immunosuppression (I). Details on the treatment of LTBI are found in the Tuberculosis section of these Guidelines (chapter 8$)(43,(46)$.

In transplant candidates with a clinical history, radiographs and/or cultures suggesting infection with TB or nontuberculous mycobacteria, a thorough evaluation for active disease should be performed, which may include CT scans, bronchoscopy or other tests as deemed clinically necessary. Any mycobacterial infection should optimally be treated with documented microbiologic and radiographic resolution before transplantation is considered.

\section{Recipient screening: fungal infections}

Pretransplant colonization with fungi such as Aspergillus is common in lung transplant recipients, particularly in cystic fibrosis patients. Such colonization should prompt a rigorous evaluation to exclude active infection. Although posttransplant aspergillosis is a feared complication, transplant clinicians have generally relied more on posttransplant preemptive and prophylactic strategies rather than pretransplant antifungal therapy for colonized patients. A pretransplant candidate with invasive fungal infection (rather than colonization) should be treated at least until there is radiographic, clinical and microbiologic resolution in order to minimize the risk of this high-mortality infection posttransplant (III). Additional information on the diagnosis, prevention and treatment of infection with Aspergillus is found in other parts of these Guidelines.

Pretransplant screening for endemic mycoses is most useful in areas endemic for coccidioidomycosis, where a pretransplant history of active disease and/or seropositivity may prompt lifelong azole prophylaxis (II-2) (50). Pretransplant screening for histoplasmosis is of limited value since latent histoplasmosis may be present with negative serology (III); instead, heightened awareness of the possibility of histoplasmosis is important when investigating a posttransplant febrile illness in a patient from an endemic area.

\section{Recipient screening: parasitic infections}

Patients from (or with prolonged travel history to) endemic areas for strongyloidiasis, including most tropical countries and parts of the southeastern United States, are at risk for development of disseminated strongyloidiasis after transplant. Screening with serology for Strongyloides is much more sensitive than stool exams, and is recommended for 
those at epidemiologic risk (III). For seropositive patients, a short course of ivermectin or thiabendazole is indicated pretransplant, although randomized data are not available. As discussed above, Toxoplasma serology should be performed in heart transplant candidates, and seronegative heart recipients with seropositive donors should receive prophylaxis (II-2) (51-53). Chagas' disease and other parasitic infections are more fully discussed elsewhere in these Guidelines (see chapter 29).

\section{Recipient screening: viral infections}

Active primary infection with viruses such as CMV, EBV, or $\mathrm{HBV}$ at the time of transplant is uncommon. Nonetheless, if active viral infection is detected in a potential recipient, transplantation should likely be delayed until the infection resolves in order to allow for development of natural immunity prior to transplant immunosuppression (III). This recommendation also extends to candidates who present for transplantation with clinical symptoms suggestive of an acute community-acquired viral infection. If there is any chance of exposure to HIV pretransplant, the potential recipient should have an HIV NAT and HIV antibody test performed (III). Viral screening of both donor and recipient are discussed in more detail above.

\section{Pretransplant immunizations}

The pretransplant evaluation presents an important opportunity to update the potential recipient's immunizations, since most vaccinations are more effective when administered prior to the onset of transplant immunosuppression (I). More detailed immunization recommendations are summarized in another section of these Guidelines (see chapter 31).

All potential recipients should be screened for vaccinepreventable infections and vaccinated as possible prior to transplant. The VZV-seronegative candidate should ideally be immunized against varicella prior to transplantation (II-3). However, if transplantation is expected imminently, it may be best to withhold vaccination with this live attenuated vaccine (III). The zoster vaccine, also a live vaccine, is currently licensed for older adults who are not immunocompromised. Further data are awaited regarding whether pretransplant zoster vaccine prevents posttransplant zoster reactivation, but at the present time it would appear reasonable to administer the zoster vaccine if the transplant candidate meets current criteria for the vaccine and if transplant is not expected within 4 weeks.

A hepatitis $B$ vaccine series should ideally be administered pretransplant to seronegative individuals (II-2); especially as a potential donor may be found who is HBsAg negative but $\mathrm{HBcAb}$ positive; in dialysis patients, the higher-dose formulation should be given. Patients with advanced liver disease are at particularly high risk for fulminant hepatitis $A$ and should receive hepatitis $A$ vaccination (II-2). This vaccine is likely more effective when administered early on in liver disease (II-2). The combined hepatitis A and B vaccine is immunogenic but data are awaited in transplant candidates and recipients.

Measles-mumps-rubella (MMR) vaccine contains live virus. Patients born in or before 1956 are presumed to have natural immunity. Patients born after 1956 who have not received a second dose of the MMR vaccine should receive a second dose, given pre- rather than posttransplant (III).

Pneumococcal vaccine should also be administered to transplant candidates over the age of 2 who have not received it within the past 5 years (III). The Tdap (tetanusdiphtheria-acellular pertussis) vaccine should be administered if the potential adult recipient has not had a tetanusdiphtheria toxoid (Td) booster within 5-10 years, and should be considered in all potential recipients in light of the increase in pertussis cases in recent years (III).

\section{Pretransplant counseling}

Preventive strategies for infection should not be confined to medications and vaccinations. Extensive education of the transplant recipient and his or her family is a very important preventive tool. Pretransplant classes and printed materials are helpful and should include information on handwashing/hand hygiene, environmental exposures, activities to avoid, food safety and handling, foodborne pathogens, pets and travel. It is also helpful for patients to have a general idea of the infections to which transplant patients are susceptible and the preventive strategies in use at their particular center. It is fundamental that patients know what to expect, what can go wrong and what is expected of them.

\section{Conclusion/future directions}

Pretransplant screening of the potential organ donor and recipient affords an opportunity to assess the feasibility and safety of transplantation, to determine the prophylaxis and preventive strategies utilized posttransplant, to detect and fully treat active infection in the potential recipient prior to transplant, to update the vaccination status of the potential recipient, and to sufficiently educate the patient and family about preventive measures. Future advances will incorporate the increasing use of rapid molecular diagnostic testing, and possibly ancillary testing for emerging pathogens in clinical practice.

\section{Acknowledgment}

This manuscript was modified from a previous guideline written by Staci A. Fischer and Robin K. Avery published in the American Journal of Transplantation 2009; 9(Suppl 4): S7-S18, and endorsed by American Society of Transplantation/Canadian Society of Transplantation.

\section{Disclosure}

The authors of this manuscript have no conflicts of interest to disclose as described by the American Journal of Transplantation. 


\section{Screening of Donor and Recipient in Solid Organ Transplantation}

\section{References}

1. Avery RK. Recipient screening prior to solid-organ transplantation. Clin Infect Dis 2002; 35: 1513-1519.

2. Avery RK. Prophylactic strategies before solid-organ transplantation. Curr Opin Infect Dis 2004; 17: 353-356.

3. Delmonico FL. Cadaver donor screening for infectious agents in solid organ transplantation. Clin Infect Dis 2000; 31: 781-786.

4. Delmonico FL, Snydman DR. Organ donor screening for infectious diseases: Review of practice and implications for transplantation. Transplant 1998; 65: 603-610.

5. Fischer SA, Avery RK and the AST Infectious Disease Community of Practice. Screening of donor and recipient prior to solid organ transplantation. Am J Transplant 2009; 9(Suppl 4): S7-S18.

6. Schaffner A. Pretransplant evaluation for infections in donors and recipients of solid organs. Clin Infect Dis 2001; 33 (Suppl 1): S9-S14.

7. Avery RK, Ljungman P. Prophylactic measures in the solid-organ recipient before transplantation. Clin Infect Dis 2001; 33 (Suppl 1): S15-S21.

8. Fishman JA, Nicolas $\mathrm{Cl}$. Infection in organ transplantation: Risk factors and evolving patterns of infection. Infect Dis Clin N Am 2010; 24: 274-283.

9. Patel R, Paya CV. Infections in solid-organ transplant recipients. Clin Microbiol Rev 1997; 10: 86-124.

10. Gottesdiener KM. Transplanted infections: Donor-to-host transmission with the allograft. Ann Intern Med 1989; 110: 1001-1016.

11. Kasiske BL, Cangro CB, Hariharan $\mathrm{S}$, et al. The evaluation of renal transplantation candidates: Clinical practice guidelines. Am J Transplant 2001; 1 (Suppl 2): 3-95.

12. Kasiske BL, Ravenscraft M, Ramos EL, Gaston RS, Bia MJ, Danovitch GM. The evaluation of living renal transplant donors. Clinical practice guidelines: Ad Hoc Clinical Practice Guidelines Subcommittee of the Patient Care and Education Committee of the American Society of Transplant Physicians. J Am Soc Nephrol 1996; 7: 2288-2313.

13. Rosengard BR, Feng S, Alfrey EJ, et al. Report of the Crystal City meeting to maximize the use of organs recovered from the cadaver donor. Am J Transplant 2002; 2: 701-711.

14. Chung RT, Feng S, Delmonico FL. Approach to the management of allograft recipients following the detection of hepatitis $B$ virus in the prospective organ donor. Am J Transplant 2001; 1: 185191.

15. Guidelines for preventing opportunistic infections among hematopoietic stem cell transplant recipients. Morb Mortal Wkly Rep 2000; 49: 1-125.

16. Guidelines for preventing transmission of human immunodeficiency virus through transplantation of human tissue and organs. Morb Mortal Wkly Rep 1994; 43: 1-17.

17. Ison MG, Hager J, Blumberg E, et al. Donor-derived disease transmission events in the United States: Data reviewed by the OPTN/UNOS Disease Transmission Advisory Committee. Am J Transplant 2009; 9: 1929-1935.

18. Ison MG, Nalesnik MA. An update on donor-derived disease transmission in organ transplantation. Am J Transplant 2011; 11: 1123-1130.

19. Srinivasan A, Burton EC, Kuehnert MJ, et al. Transmission of rabies virus from an organ donor to four transplant recipients. $\mathrm{N}$ Engl J Med 2005; 352: 1103-1111.

20. Fischer SA, Graham MB, Kuehnert MJ, et al. Transmission of lymphocytic choriomeningitis virus by organ transplantation. $\mathrm{N}$ Engl J Med 2006; 354: 2235-2249.
21. Iwamoto M, Jernigan DB, Guasch A, et al. Transmission of West Nile virus from an organ donor to four transplant recipients. N Engl J Med 2003; 348: 2196-2203.

22. Simonds RJ, Holmberg SD, Hurwitz RL, et al. Transmission of human immunodeficiency virus type 1 from a seronegative organ and tissue donor. N Engl J Med 1992; 326: 726-732.

23. Ison MG, Llata $E$, Conover CS, et al. Transmission of human immunodeficiency virus and hepatitis $C$ virus from an organ donor to four transplant recipients. Am J Transplant 2011; 11: 12181225.

24. Ahn J, Cohen SM. Transmission of human immunodeficiency virus and hepatitis $C$ virus through liver transplantation. Liver Transpl 2008; 14: 1603-1608.

25. Fishman JA, Strong DM, Kuehnert MJ. Organ and tissue safety workshop 2007: Advances and challenges. Cell Tissue Bank 2009; 10: 271-280.

26. Strong DM, Seem D, Taylor G, et al. Development of a transplantation transmission sentinel network to improve safety and traceability of organ and tissues. Cell Tissue Bank 2010; 11: 335343.

27. Fishman JA, Greenwald MA, Kuehnert MJ. Enhancing transplant safety: A new era in the microbiologic evaluation of organ donors? Am J Transplant 2007; 7: 2652-2654.

28. Humar A, Fishman JA. Donor-derived infection: Old problem, new solutions? Am J Transplant 2008; 8: 1087-1088.

29. Centers for Disease Control and Prevention. HIV transmitted from a living organ donor-New York City, 2009. Morbid Mortal Wkly Rep 2011; 60: 297-301.

30. Humar A, Morris M, Blumberg E, et al. Nucleic acid testing (NAT) of organ donors: Is the 'best' test the right test? A consensus conference report. Am J Transplant 2010; 10: 889-899.

31. Cortes NJ, Afzali B, MacLean D, et al. Transmission of syphilis by solid organ transplantation. Am J Transplant 2006; 6: 2497-2499.

32. Doig RL, Boyd PJ, Eykyn S. Staphylococcus aureus transmitted in transplanted kidneys. Lancet 1975; 2: 243-245.

33. Kumar D, Cattral MS, Robicsek A, Gaudreau C, Humar A. Outbreak of Pseudomonas aeruginosa by multiple organ transplantation from a common donor. Transplant 2003; 75: 1053-1055.

34. Fernando ON, Higgins AF, Moorhead JF. Letter: Secondary haemorrhage after renal transplantation. Lancet 1976; 2: 368.

35. Nelson PW, Delmonico FL, Tolkoff-Rubin NE, et al. Unsuspected donor Pseudomonas infection causing arterial disruption after renal transplantation. Transplant 1984; 37: 313-314.

36. Freeman RB, Giatras I, Falagas ME, et al. Outcome of transplantation of organs procured from bacteremic donors. Transplant 1999; 68: 1107-1111.

37. Lopez-Navidad A, Domingo P, Caballero F, Gonzalez C, Santiago C. Successful transplantation of organs retrieved from donors with bacterial meningitis. Transplant 1997; 64: 365-368.

38. Ruiz I, Gavalda J, Monforte V, et al. Donor-to-host transmission of bacterial and fungal infections in lung transplantation. Am J Transplant 2006; 6: 178-182.

39. McCoy GC, Loening S, Braun WE, Magnusson MO, Banowsky $\mathrm{LH}, \mathrm{McHenry} M \mathrm{MC}$. The fate of cadaver renal allografts contaminated before transplantation. Transplant 1975; 20: 467-472.

40. Mossad SB, Avery RK, Goormastic M, Hobbs RE, Stewart RW. Significance of positive cultures from donor left atrium and postpreservation fluid in heart transplantation. Transplant 1997; 64: 1209-1210.

41. Matignon M, Botterel F, Audard V, et al. Outcome of renal transplantation in eight patients with Candida sp. contamination of preservation fluid. Am J Transplant 2008; 8: 697-700. 
42. Sauget M, Verdy S, Slekovec C, et al. Bacterial contamination of organ graft preservation solution and infection after transplantation. Transpl Infect Dis 2011; 13: 331-334.

43. Singh N, Paterson DL. Mycobacterium tuberculosis infection in solid-organ transplant recipients: Impact and implications for management. Clin Infect Dis 1998; 27: 1266-1277.

44. Manuel O, Humar A, Preiksaitis J, et al. Comparison of quantiferon-TB gold with tuberculin skin test for detecting latent tuberculosis infection prior to liver transplantation. Am J Transplant 2007; 7: 2797-2801.

45. Aguado JM, Torre-Cisneros J, Fortun J, et al. Tuberculosis in solid organ transplant recipients: Consensus statement of the Group for the Study of Infection in Transplant Recipients (GESITRA) of the Spanish Society of Infectious Diseases and Clinical Microbiology. Clin Infect Dis 2009; 48: 1276-1284.

46. Antony SJ, Ynares C, Dummer JS. Isoniazid hepatotoxicity in renal transplant recipients. Clin Transplant 1997; 11: 34-37.

47. Morris MI, Daly JS, Blumberg E, et al. Diagnosis and management of tuberculosis in transplant donors: A donor derived infections consensus conference report. Am J Transplant 2012; 12: 2288-300.

48. Limaye AP, Connolly PA, Sagar M, et al. Transmission of Histoplasma capsulatum by organ transplantation. N Engl J Med 2000; 343: 1163-1166.

49. Tripathy U, Yung GL, Kriett JM, Thistlethwaite PA, Kapelanski DP, Jamieson SW. Donor transfer of pulmonary coccidioidomycosis in lung transplantation. Ann Thorac Surg 2002; 73: 306-308.

50. Blair JE, Logan JL. Coccidioidomycosis in solid organ transplantation. Clin Infect Dis 2001; 33: 1536-1544.

51. Wreghitt TG, Gray JJ, Pavel P, et al. Efficacy of pyrimethamine for the prevention of donor-acquired Toxoplasma gondii infection in heart and heart-lung transplant patients. Transpl Int 1992; 5: 197-200.

52. Rogers NM, Peh CA, Faull R, Pannell M, Cooper J, Russ GR. Transmission of toxoplasmosis in two renal allograft recipients receiving an organ from the same donor. Transpl Infect Dis 2008; 10: 71-74.

53. Gourishankar S, Doucette K, Fenton J, et al. The use of donor and recipient screening for toxoplasma in the era of universal trimethoprim sulfamethoxazole prophylaxis. Transplant 2008; 85: 980-985.

54. Chagas disease after organ transplantation-Los Angeles, California, 2006. Morb Mortal Wkly Rep 2006; 55: 798-800.

55. Chin-Hong PV, Schwartz BS, Bern C, et al. Screening and treatment of Chagas disease in organ transplant recipients in the United States: Recommendations from the Chagas in Transplant Working Group. Am J Transplant 2011; 11: 672-680.

56. Falagas ME, Snydman DR, Griffith J, Ruthazer R, Werner BG. Effect of cytomegalovirus infection status on first-year mortality rates among orthotopic liver transplant recipients. Ann Intern Med 1997; 126: 275-279.

57. Falagas ME, Snydman DR, Griffith J, Werner BG, Freeman R, Rohrer R. Clinical and epidemiological predictors of recurrent cytomegalovirus disease in orthotopic liver transplant recipients. Clin Infect Dis 1997; 25: 314-317.

58. Kalil AC, Levitsky J, Lyden E, Stoner J, Freifeld AG. Metaanalysis: The efficacy of strategies to prevent organ disease by cytomegalovirus in solid organ transplant recipients. Ann Intern Med 2005; 143: 870-880.

59. Green M, Cacciarelli TV, Mazariegos GV, et al. Serial measurement of Epstein-Barr viral load in peripheral blood in pediatric liver transplant recipients during treatment for posttransplant lymphoproliferative disease. Transplant 1998; 66: 1641-1644.
60. Preiksaitis JK, Keay S. Diagnosis and management of posttransplant lymphoproliferative disorder in solid-organ transplant recipients. Clin Infect Dis 2001; 33 (Suppl 1): S38-S46.

61. McDiarmid SV, Jordan S, Kim GS, et al. Prevention and preemptive therapy of postransplant lymphoproliferative disease in pediatric liver recipients. Transplant 1998; 66: 1604-1611.

62. Parker A, Bowles K, Bradley JA, et al. Diagnosis of post-transplant lymphoproliferative disorder in solid organ transplant recipientsBCSH and BTS guidelines. Brit J Haematol 2010; 149: 675692.

63. Dockrell DH, Mendez JC, Jones M, et al. Human herpesvirus 6 seronegativity before transplantation predicts the occurrence of fungal infection in liver transplant recipients. Transplant 1999; 67: 399-403.

64. Regamey N, Tamm M, Wernli M, et al. Transmission of human herpesvirus 8 infection from renal-transplant donors to recipients. N Engl J Med 1998; 339: 1358-1363.

65. Gomez-Roman JJ, Ocejo-Vinyals JG, Sanchez-Velasco P, LeyvaCobian F, Val-Bernal JF. Presence of human herpesvirus 8 DNA sequences in renal transplantation-associated pleural Kaposi sarcoma. Arch Pathol Lab Med 1999; 123: 1269-1273.

66. Kapelushnik J, Ariad S, Benharroch D, et al. Post renal transplantation human herpesvirus 8-associated lymphoproliferative disorder and Kaposi's sarcoma. Br J Haematol 2001; 113: 425-428.

67. Wachs ME, Amend WJ, Ascher NL, et al. The risk of transmission of hepatitis B from $\mathrm{HBsAg}(-), \mathrm{HBcAb}(+), \mathrm{HB} \operatorname{lgM}(-)$ organ donors. Transplant 1995; 59: 230-234.

68. Madayag RM, Johnson LB, Bartlett ST, et al. Use of renal allografts from donors positive for hepatitis $B$ core antibody confers minimal risk for subsequent development of clinical hepatitis $B$ virus disease. Transplant 1997; 64: 1781-1786.

69. Dodson SF, Bonham CA, Geller DA, Cacciarelli TV, Rakela J, Fung $J J$. Prevention of de novo hepatitis $B$ infection in recipients of hepatic allografts from anti-HBc positive donors. Transplant 1999; 68: 1058-1061.

70. Younossi ZM, Braun WE, Protiva DA, Gifford RW, Jr., Straffon RA. Chronic viral hepatitis in renal transplant recipients with allografts functioning for more than 20 years. Transplant 1999; 67: 272-275.

71. Pinney SP, Cheema FH, Hammond K, et al. Acceptable recipient outcomes with the use of hearts from donors with hepatitis $B$ core antibodies. J Heart Lung Transplant 2005; 24: 34-37.

72. Lee WC, Wu MJ, Cheng CH, Chen CH, Shu KH, Lian JD. Lamivudine is effective for the treatment of reactivation of hepatitis $\mathrm{B}$ virus and fulminant hepatic failure in renal transplant recipients. Am J Kidney Dis 2001; 38: 1074-1081.

73. Pereira BJ, Natov SN, Bouthot BA, et al. Effects of hepatitis C infection and renal transplantation on survival in end-stage renal disease. Kidney Int 1998; 53: 1374-1381.

74. Ong JP, Barnes DS, Younossi ZM, et al. Outcome of de novo hepatitis $C$ virus infection in heart transplant recipients. Hepatology 1999; 30: 1293-1298.

75. Roland ME, Barin B, Carlson L, et al. HIV-infected liver and kidney transplant recipients: 1- and 3-year outcomes. Am J Transplant 2008; 8: 355-365.

76. Stock PG, Barin B, Murphy B, et al. Outcomes of kidney transplantation in HIV-infected recipients. N Engl J Med 2010; 363: 2004-2014.

77. Organ Procurement and Transplantation Network/United Network for Organ Sharing (OPTN/UNOS). Guidance for HTLV-1 screening and confirmation in potential donors and reporting potential HTLV-1 infection. Published online 6/29/2011, accessed at http://optn.transplant.hrsa.gov/SharedContentDocuments/ Guidance_DTAC_HTLV_06--2011.pdf on August 12, 2012. 
Screening of Donor and Recipient in Solid Organ Transplantation

78. Ad Hoc Disease Transmission Advisory Committee (DTAC). Proposal to modify requirements for mandatory HTLV-1/2 testing for all potential deceased donors. Accessed at http://optn.transplant. hrsa.gov/PublicComment/pubcommentPropSub_252.pdf on August 12, 2012.

79. Marvin MR, Brock GN, Kwarteng MS, et al. Increasing utilization of human T-cell lymphotropic virus (+) donors in liver transplantation: Is it safe? Transplant 2009; 87: 1180-1190.

80. Nowicki MJ, Marsuoka L, Brucal D, et al. High seroprevlance of anti-HTLV-I/II antibodies among solid organ donors necessitates confirmatory testing. Transplant 2006; 82: 1210-1213.

81. Kaul DR, Taranto S, Alexander C, et al. Donor screening for human T-cell phymophtropic virus $1 / 2$; changing paradigms for changing testing capacity. Am J Transplant 2010; 10: 207-213.

82. Toro C, Rodes B, Poveda E, Soriano V. Rapid development of subacute myelopathy in three organ transplant recipients after transmission of human T-cell lymphotropic virus type I from a single donor. Transplant 2003; 75: 102-104.

83. Zarranz Imirizaldu JJ, Gomez Esteban JC, Rouco Axpe I, et al. Post-transplantation HTLV-1 myelopathy in three recipients from a single donor. J Neurol Neurosurg Psychiatry 2003; 74: 10801084.

84. Gonzalez-Perez MP, Munoz-Juarez L, et al. Human T-cell leukemia virus type I infection in various recipients of transplants from the same donor. Transplant 2003; 75: 10061011.

85. Nakamura N, Tamaru S, Ohshima K, Tanaka M, Arakaki Y, Miyauchi T. Prognosis of HTLV-I-positive renal transplant recipients. Transplant Proc 2005; 37: 1779-1782.

86. Fischer SA. Emerging viruses in transplantation: There is more to infection after transplant than CMV and EBV. Transplant 2008; 86: 1327-1339.

87. Kumar D, Humar A. Emerging viral infections in transplant recipients. Curr Opin Infect Dis 2005; 18: 337-341.

88. Update: Investigations of West Nile virus infections in recipients of organ transplantation and blood transfusion-Michigan, 2002. Morb Mortal Wkly Rep 2002; 51: 879.

89. Kiberd BA, Forward K. Screening for West Nile virus in organ transplantation: A medical decision analysis. Am J Transplant 2004; 4: 1296-1301.

90. Centers for Disease Control and Prevention. Lymphocytic choriomeningitis virus infection in organ transplant recipientsMassachusetts, Rhode Island, 2006. Morb Mortal Wkly Rep 1005; 543(dispatch): 1-2.

91. Brief report: Lymphocytic choriomeningitis virus transmitted through solid organ transplantation-Massachusetts, 2008. Morb Mortal Wkly Rep 2008; 57: 799-801.

92. Palacios G, Druce J, Du L, et al. A new arenavirus in a cluster of fatal transplant-associated diseases. N Engl J Med 2008; 358: 991-998.

93. Amman BR, Pavlin BI, Albarino CG, et al. Pet rodents and fatal lymphocytic choriomeningitis in transplant patients. Emerg Infect Dis 2007; 13: 719-725.
94. MacNeil A, Stroher U, Farnon E, et al. Solid organ transplantassociated lymphocytic choriomeningitis, United States, 2011. Emerg Infect Dis 2012; 18: 1256-1262,

95. Update: Interim guidance for minimizing risk for human lymphocytic choriomeningitis virus infection associated with pet rodents. Morb Mortal Wkly Rep 2005; 54: 799-801.

96. Kusne S, Smilack J. Transmission of rabies virus from an organ donor to four transplant recipients. Liver Transpl 2005; 11: 12951297.

97. Kumar D, Tellier R, Draker R, Levy G, Humar A. Severe acute respiratory syndrome (SARS) in a liver transplant recipient and guidelines for donor SARS screening. Am J Transplant 2003; 3: 977-981.

98. Gavada J, Cabral E, Alonso E, et al. Influenza A H1N1/2009 infection in pediatric solid organ transplant recipients. Transpl Infect Dis 2012; 0: 1-5.

99. Kumar D, Morris MI, Kotton CN, et al. Guidance on novel influenza $\mathrm{A} / \mathrm{H} 1 \mathrm{~N} 1$ in solid organ transplant recipients. Am J Transplant 2010; 10: 18-25.

100. Cho JH, Kim CD, Kim MS, et al. The impact of A (H1N1) pdm09 infection on renal transplant recipients: A multicenter cohort study. J Infect 2012; 65: 88-90.

101. Halliday N, Wilmore S, Griffiths PD, et al. Risk of transmission of H1N1 influenza by solid organ transplantation in the United Kingdom. Transplantation 2012; 93: 551-554.

102. Cockbain AJ, Jacob M, Ecuyer, et al. Transplantation of solid organs procured from influenza A H1N1 infected donors. Transpl Int 2011; 24: e107-e110

103. Fishman JA. New technologies for infectious screening of organ donors. Transplant Proc 2011; 43: 2443-2445.

104. Herrmann M, Wetand M, Greshake B, et al. Left ventricular assist device infection is associated with increased mortality but is not a contraindication to transplantation. Circulation 1997; 95: 814817.

105. Simon D, Fischer S, Grossman A, et al. Left ventricular assist device-related infection: Treatment and outcome. Clin Infect Dis 2005; 40: 1108-1115.

106. Avery RK. Infections after lung transplantation. Semin Respir Crit Care Med 2006; 27: 544-551.

107. Aris RM, Routh JC, LiPuma JJ, Heath DG, Gilligan PH. Lung transplantation for cystic fibrosis patients with Burkholderia cepacia complex. Survival linked to genomovar type. Am J Respir Crit Care Med 2001; 164: 2102-2106.

108. Remund KF, Best M, Egan JJ. Infections relevant to lung transplantation. Proc Am Thorac Soc 2009; 6: 94-100.

109. Broussard V, Guillemain R, Grenet D, et al. Clinical outcome following lung transplantation in cystic fibrosis patients colonized with Burkoldheria cepacia complex; results from two French centers. Thorax 2008; 63: 732-737.

110. Mazurek GH, Villarino ME. Guidelines for using the QuantiFERON-TB test for diagnosing latent Mycobacterium tuberculosis infection. Centers for Disease Control and Prevention. Morb Mortal Wkly Rep 2003; 52: 15-18. 